\title{
Confidencialidad y derechos de autor en un proyecto de intranet
}

\author{
Por Josep Vives-Gràcia
}

\begin{abstract}
Resumen: Se abordan dos cuestiones de índole legal que afectan a la planificación, desarrollo y uso de intranets. Derechos de autor y protección de datos personales son dos aspectos básicos del derecho de la información que deben tenerse en cuenta por los responsables de la intranet de una organización. Aunque la naturaleza del derecho de propiedad intelectual y de la protección de los datos personales son totalmente diferentes, se tratan conjuntamente en dicho trabajo bajo la perspectiva de cómo deben ser gestionados por los profesionales de la información. En los últimos años se ha podido observar como la tecnología puede suponer un aumento de las infracciones de las leyes de derecho de autor o de la protección de datos personales, conflictividad que podría darse en nuestras intranets si no se toman las medidas adecuadas que concilien los intereses tanto de los usuarios de información como la de los titulares de los datos personales o los propietarios de los derechos de autor.
\end{abstract}

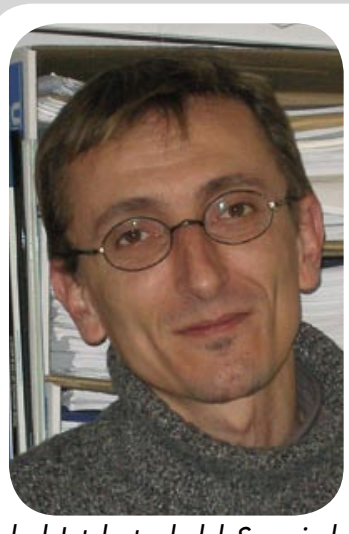

Josep Vives-Gràcia es diplomado en biblioteconomía y documentación y licenciado en documentación. Actualmente es responsable del Área de Servicios para la Investigación de la biblioteca de la Escola Politècnica Superior d'Enginyeria de Vilanova i la Geltrú de la Universitat Politècnica de Catalunya. Coordinador del Servicio de Propiedad Intelectual del Servei de Biblioteques de la UPC. Miembro del Grupo de Trabajo Bibliotecas y Propiedad Intelectual de Fesabid.

Palabras clave: Derecho de autor, Propiedad intelectual, Copyright, Protección de datos personales, Privacidad, Intranets.

\section{Title: Confidentiality and copyright in an intranet project}

Abstract: This study addresses two questions in the legal realm that affect the planning, development, and use of intranets. Protection of the author's rights and protection of the user's personal information are two basic considerations that must be taken into account by those responsible for an organization's intranet. Although intellectual property rights and confidentiality are totally different in nature, both are discussed in this article from the perspective of how they should be managed by information professionals. In recent years we have seen how technology can contribute to violation of copyright law and personal confidentiality. This conflict can occur in our intranets if proper measures are not taken to reconcile the interests of all users, of those whose personal information must be protected, and of copyright holders.

Keywords: Copyright, Privacy, Personal data protection, Intellectual property, Intranets.

Vives-Gràcia, Josep. "Confidencialidad y derechos de autor en un proyecto de intranet". En: El profesional de la información, 2007, mayo-junio, v. 16, n. 3, pp. 188-205.

DOI: 10.3145/epi.2007.may.03

"Only one thing is impossible for God: to find any sense in any copyright law on the planet" (Mark Twain).

Las intranets, así como otros sistemas de gestión de información, se han convertido en elementos indispensables para el quehacer diario de muchas organizaciones. Pocas son las empresas o instituciones que actualmente no dispongan de una red informática interna en la que se pueda almacenar y distribuir información de interés para sus miembros.

En los últimos años no solamente se ha incrementado su número, sino que al mismo tiempo cada vez son más las personas que tienen acceso a estos sistemas, tanto para consultar contenidos como para añadir información digitalizada.

A los estudios relacionados con los aspectos técnicos informáticos (configuración de la red, tipos de servidores, lenguajes de programación, etc.), se ha ido sumando el análisis de las implicaciones que desde el punto de vista jurídico comporta la gestión de la información en dichas estructuras.

En este trabajo intentaremos abordar dos aspectos básicos en la gestión de la información "interna” de la organización: la confidencialidad de los datos que se almacenan y el derecho de autor de los documentos que se ponen a disposición de los usuarios de una intranet $\mathrm{u}$ otros sistemas análogos.

\section{Protección de datos personales y derecho de autor}

Desde el punto de vista jurídico son dos aspectos que no tienen porque estudiarse conjuntamente, es más, la legislación los aborda de manera separada y partien- 
do de principios muy diferentes. Sin embargo, para el profesional de la información en tanto que responsable del sistema de información de la organización, es necesario que se estudien en paralelo ya que son dos de las cuestiones que más incidencias tienen en la resolución de problemas relacionados con el marco jurídico de las intranets.

Desde la experiencia profesional, en dos años de trabajo en el Servicio de Propiedad Intelectual (SEPI) del Servei de Biblioteques i Documentació de la Universitat Politècnica de Catalunya ${ }^{1}$ no han sido pocas las consultas que se han recibido que tenían más que ver con la protección de datos personales que con la propiedad intelectual ${ }^{2}$.

No nos alargaremos en justificar la importancia de gestionar de manera adecuada los derechos de autor ni en la necesidad de velar por el correcto tratamiento de los datos de carácter personal que se puedan encontrar localizados en un entorno de intranet o similares, nos remitimos en todo caso a la cada vez más abundante literatura sobre el tema ${ }^{3}$.

Tampoco parece oportuno en este trabajo discutir sobre qué profesionales debe recaer este cometido. Parece claro que en las grandes organizaciones serán los servicios jurídicos los responsables últimos de la política sobre esta materia, mientras que las organizaciones que no dispongan de dicho apoyo deberán preparar adecuadamente (recibiendo la formación externa si cabe) a su personal porque, dicho sea de paso, la ley obliga a grandes, medianos y pequeños. En una u otra situación, el bibliotecario-documentalista puede participar plenamente en la gestión conjunta de esos derechos y en todo caso es la organización la que debe plantearse qué conocimientos mínimos deben de disponer todos los miembros de su estructura al respecto de dicha gestión.

La tecnología, que en la mayoría de los casos nos ayuda a trabajar de forma más rápida y más eficiente, nos crea al mismo tiempo más obligaciones. Un ejemplo paradigmático lo tenemos en la elaboración de los boletines o resúmenes de prensa que tradicionalmente se confeccionaban a partir de fotocopias y posteriormente eran distribuidos entre los miembros de una organización. Ciertamente la actual utilización combinada de ediciones electrónicas con la inclusión parcial o íntegra del texto completo, ha permitido su reducción de costes y su proliferación. Como contrapartida a su generalización han surgido problemas relativos a la explotación de estos documentos informativos y más en el caso de que dicho disfrute tenga un objetivo económico (como en el caso de los servicios de press clipping). Igualmente en lo que respecta a la difusión de informaciones (noticias, publicidad, etc.), la utilización del correo electrónico ha propiciado la aparición de "nuevas" técnicas comunica- tivas; es precisamente esta proliferación la que ha obligado a plantearse hasta que punto puede ser "invadido" nuestro buzón de mensajes.

Nuevas soluciones, en definitiva, conllevan nuevos problemas.

\section{"La tecnología, que en la mayoría de los casos nos ayuda a trabajar de forma más rápida y más eficiente, nos crea al mismo tiempo más obligaciones"}

La utilización intensiva de la tecnología en la gestión documental incide de manera plena en dos tipos de derechos diferentes: el derecho de los autores a su obra y el de las personas a que sus datos personales sean tratados de forma rigurosa y segura. Las diferentes legislaciones europeas se han ido adaptando al nuevo entorno tecnológico de la sociedad de la información modificando y ampliando sus respectivos marcos legislativos, en especial por la necesidad de incorporar al ordenamiento jurídico nacional las diferentes directivas comunitarias que el Parlamento Europeo ha ido aprobando hasta el momento.

La Constitución española (CE), no obstante, no es ajena al fenómeno de los derechos de autor y a la protección de datos personales. Al ser un texto "joven", recogió en el momento de su promulgación los principios básicos a partir de los que se ha desplegado la legislación actual. Así, en su artículo 18.4 proclama que "la ley limitará el uso de la informática para garantizar el honor y la intimidad personal y familiar de los ciudadanos y el ejercicio pleno de sus derechos". Dicho precepto completa otros tres epígrafes del artículo 18 en los que se protege el derecho al honor, intimidad y derecho a la imagen (18.1), la inviolabilidad del domicilio (18.2) y el secreto de las comunicaciones (18.3).

Todos estos artículos forman parte del capítulo correspondiente a los llamados derechos fundamentales de la ciudadanía. De esta forma, tan "importante" sería el derecho que tenemos a que nadie entre en nuestro domicilio sin el correspondiente permiso (excepto en los casos previstos por la ley) como el de la protección de nuestros datos personales. Al tratarse de un derecho fundamental, la ley de protección de datos tiene el rango de "ley orgánica", el mismo rango por ejemplo, con el se aprueban los estatutos de autonomía (art. 81.1 $\mathrm{CE})$.

Caso aparte representa la propiedad intelectual ya que si bien para algunos autores (Rodríguez Tapia, 
1997) no existe duda en que se incluya en el derecho fundamental a "la producción y creación literaria, artística, científica y técnica" (art. 20.1.b de la CE), para otros autores (Bercovitz, 1997) el derecho de autor no formaría parte del grupo de los considerados como fundamentales de los ciudadanos ya que, por ejemplo, el legislador nunca ha dado el rango de "ley orgánica" las sucesivas leyes de propiedad intelectual españolas. De hecho, el concepto "propiedad intelectual" aparece mencionado literalmente en el art. 149.1.9 de la $\mathrm{CE}$ atribuyendo al Estado la competencia exclusiva de dicha materia ${ }^{4}$, por lo que cabe deducir que en caso de que los constitucionalistas lo hubieran querido incluir con los derechos fundamentales, lo habrían hecho constar expresamente como en el artículo 149.1.9 de asignación de competencias.

Esta discusión, que podría parecernos meramente académica y sin más importancia, resulta especialmente trascendental en el momento de "limitar" o "someter" este derecho al interés general. Así, el derecho a la protección de los datos personales, al ser un derecho fundamental solamente se puede limitar en los casos que más tarde analizaremos.

Más controvertida, y lo sabemos los bibliotecariosdocumentalistas, es la discusión sobre los límites de la propiedad intelectual. A estos efectos podemos afirmar que un primer aspecto a considerar en cualquier legislación sobre este tema lo representa el acceso a la cultura (art. $44 \mathrm{CE}$ : "los poderes públicos promoverán y tutelarán el acceso a la cultura, a la que todos tienen derecho" (Clavell, 1999). Así, la legislación al respecto prevé una serie de límites y excepciones que tienden a conjugar tanto el derecho del autor a la explotación de su obra como el de la sociedad al acceso a ese material.

\section{"La legislación de derechos de autor prevé una serie de límites y excepciones que tienden a conjugar tanto el derecho del autor a la explotación de su obra como el de la sociedad al acceso a ese material"}

Para acabar con esta primera aproximación a la naturaleza constitucional de estos dos derechos, solamente una reflexión más, a nuestro entender inquietante. En el texto de la Constitución europea ${ }^{5}$ se reconoce efectivamente el derecho a la propiedad intelectual y su protección dentro de la Carta de los derechos fundamentales de la unión (art. II-77) mientras que el derecho al acceso a la cultura sencillamente no aparece. A nuestro entender se hace un flaco favor a las instituciones cuyo cometido es la difusión del patrimonio bibliográfico, documental y patrimonial. Cabe decir que la protección de datos personales sí que viene reconocida en el texto europeo como derecho fundamental (art. II-68).

\section{"En la Constitución europea se reconoce el derecho a la propiedad intelectual y su protección, mientras que el de acceso a la cultura no aparece"}

\section{Legislación básica a considerar}

Dejando a un lado las referencias al texto constitucional español y europeo, la legislación básica de referencia es la siguiente:

\subsection{Derechos de autor}

Real Decreto Legislativo 1/1996, de 12 de abril, por el que se aprueba el Texto Refundido de la Ley de Propiedad Intelectual, regularizando, aclarando y armonizando las disposiciones legales vigentes sobre la materia ( $L P I)$. A efectos prácticos de consulta recomendamos la versión recogida en el proyecto Norm@civil ya que incluye las modificaciones realizadas posteriormente sobre el texto refundido por la Ley 5/1998, de 6 de marzo sobre protección de bases de datos.

http://civil.udg.es/normacivil/estatal/reals/Lpi.html

Dicho texto debe completarse con la recientemente aprobada Ley 23/2006, de 7 de julio, por la que se modifica el texto refundido de la Ley de Propiedad Intelectual y que introduce cambios importantes en la normativa actual.

http://www.boe.es/boe/dias/2006/07/08/pdfs/ A25561-25572.pdf\#search $=\% 22$ Ley\%2023\%2F2 $006 \% 22$

Poco antes de la aprobación de esta reforma se publicó otra ley modificando también algunos aspectos de la legislación básica pero que no serán objeto de comentario en este trabajo ya que no afectan a los temas que se tratan: Ley 19/2006, de 5 de junio, por la que se amplían los medios de tutela de los derechos de propiedad intelectual e industrial y se establecen normas procesales para facilitar la aplicación de diversos reglamentos comunitarios.

http://www.boe.es/boe/dias/2006/06/06/pdfs/ A21230-21238.pdf\#search $=\% 22$ Ley\%2019\%2F2 $006 \% 22$ 


\subsection{Protección de datos personales}

La legislación básica la encontramos en la Ley $\mathrm{Or}$ gánica 15/1999, de 13 de diciembre, de Protección de Datos de Carácter Personal (LOPD). Recomendamos también la edición del proyecto Norm@ @ivil que incluye las anulaciones de algunos de sus artículos en virtud de una sentencia del Tribunal Constitucional.

http://civil.udg.es/normacivil/estatal/persona/PF/ Lo15-99.htm

Algunos aspectos de la legislación básica deben complementarse con el Real Decreto 994/1999, de 11 de junio, por el que se aprueba el Reglamento de medidas de seguridad de los ficheros automatizados que contengan datos de carácter personal.

http://www.ua.es/es/normativa/datospersonales/pdfs/ RD994-1999.pdf\#search=\%22Real\%20Decreto\%209 94\%2F $1999 \% 22$

En el caso de determinados tipos de documentos deberá considerarse igualmente la legislación estatal y autonómica que regula la gestión de dichos documentos, como por ejemplo el caso de las historias clínicas (Fernández, 2006), los documentos contables, etc. Igualmente, debe observarse la legislación autonómica, si existiera, sobre protección de datos y que, por no modificar la legislación básica, no contemplamos en este trabajo.

\section{Ojos que no ven, ¿corazón que no siente?}

A efectos de este trabajo consideramos intranet en el sentido más amplio posible, es decir, una red de ordenadores conectados entre sí que permite la gestión de información y cuyo acceso no es universal. Incluimos pues en esta definición los entornos basados en tecnología web, pero también otros tipos de sistemas de intercambio de información como unidades de disco o servidores compartidos, etc.

Cuando se evalúen cuales son los aspectos de propiedad intelectual y protección de datos que debemos considerar en un entorno de intranet, la primera tentación podría ser "aligerar" el grado de exigencia dado que nos encontramos en un entorno básicamente de acceso restringido. Esto nos podría llevar a pensar, erróneamente, que las reglas jurídicas a aplicar en un entorno de internet (acceso público) son diferentes de las que corresponden a una intranet (acceso restringido). Pues bien, no es así o al menos no es exactamente así.

Por lo que respecta a temas de derechos de autor, no existe ninguna diferencia formal que diferencie la protección de un documento disponible electrónicamente a través de una intranet o directamente en un web de acceso público. Cuando ponemos un ma- terial a disposición de los usuarios estamos realizando, en cualquier caso, lo que se califica como acto de comunicación pública (art. 20 de la $L P I$ ): "1. Se entenderá por comunicación pública todo acto por el cual una pluralidad de personas pueda tener acceso a la obra sin previa distribución de ejemplares a cada una de ellas. No se considerará pública la comunicación cuando se celebre dentro de un ámbito estrictamente doméstico que no esté integrado o conectado a una red de difusión de cualquier tipo". Por si cupiera algún tipo de duda al respecto, la reforma de la $L P I$ (Ley 23/2006) acabada de promulgar, establece en el apartado tercero de su artículo único, que tendrá la consideración de comunicación pública: "La puesta a disposición del público de obras, por procedimientos alámbricos o inalámbricos, de tal forma que cualquier persona pueda acceder a ellas desde el lugar y en el momento que elija".

Así pues, ningún documento protegido por la $L P I$ (la mayoría con los que trabajan los bibliotecarios-documentalistas) puede ser comunicado públicamente (por ejemplo, colgado en una intranet) si no se dispone de la preceptiva autorización de los titulares de los derechos de explotación o pueda acogerse a algún límite o excepción prevista en la ley.

Caso aparte representa la consideración de la puesta a disposición en una intranet o en un web de datos personales protegidos por la $L O P D$. En este caso no se puede decir que la diferencia venga dada tampoco por hacerlo en una intranet o una web sino por el tipo de acceso que se da a los datos. Desde ambos sitios puede darse acceso a datos personales, pero la legalidad de la acción vendrá condicionada, de manera general, por quiénes tienen acceso a dichos datos y por si se han gestionado las adecuadas autorizaciones en el caso que sean necesarias. Dicho de otra forma, facilitar la consulta de los datos personales de los trabajadores de una organización no depende tanto de si el directorio se consulta a través de una intranet o desde la web de la organización, sino de quiénes los consultan y en qué condiciones (Apdcm, 2005). Lo que la ley nos exigirá es recabar el permiso de las personas de las que se facilitan los datos si el acceso a la información es libre o el deber a informarlos de la habilitación de dicha consulta si está restringido solamente a los miembros de la organización, excepto en los casos previstos en la misma ley.

Por tanto, debemos tener muy presente que, aunque los documentos protegidos por la $L P I$ o los datos personales sometidos a la $L O P D$ se encuentren solamente en nuestra intranet, los niveles de exigencia legal son los mismos. En no pocos casos, las denuncias por supuestos incumplimientos de la protección de datos vienen dados por los mismos miembros de la organización. 


\section{EI derecho de autor en los documentos de una intranet}

Anteriormente ya hemos expuesto algunos principios de la legislación en propiedad intelectual que debemos considerar para una correcta gestión de los derechos de autor de los documentos guardados en una intranet. "Gestionar" es precisamente la palabra adecuada que deberíamos considerar cuando tratemos de acomodar nuestras acciones a la legislación. Tanto la postura de incumplir la legislación aplicable "porque estamos en nuestra intranet", como la posición opuesta, la de no permitir la presencia de ningún documento "por si acaso" acabarían siendo un problema para la organización. En el primer supuesto, es un delito tipificado y perseguido. En el segundo caso, desaconsejar a los miembros de una organización el uso en una intranet de documentos protegidos por la LPI impediría beneficiarse de la indudable utilidad que su uso representa.. Por esto nuestra recomendación pasa por intentar gestionar de manera correcta los derechos de autor de los documentos que debemos incorporar en nuestro sistema de información.

Intentaremos en este trabajo ofrecer una metodología simple de análisis con las correspondientes bases legales. Las limitaciones de espacio no permiten, sin embargo tratar en profundidad todos estos aspectos, por lo que remitimos a los trabajos de Altarriba (1997), Riera (2005) y Vives (2005), para profundizar en el tema ${ }^{6}$.

\subsection{Existencia de condiciones de uso de los do- cumentos a difundir a través de la intranet}

Nos referiremos a continuación a aquellos documentos de los cuales la organización no detenta sus derechos de explotación. Antes es necesario conocer si el documento ha sido adquirido bajo licencia (como es el caso de la mayoría de recursos electrónicos) y que puede ser "comercial", si se ha comprado previo pago, o "gratuita" (por ejemplo distribuido bajo licencia Creative Commons). En estos casos necesitaremos leer el contenido de la licencia o contrato que hayamos aceptado para saber si el uso que le queremos dar (comunicación pública) es conforme a sus cláusulas. Esto es especialmente importante en el entorno académico o en organizaciones que dispongan de colecciones electrónicas de documentos de pago (colegios profesionales, consultorías, despachos de abogados, etc.).

\subsection{Determinación de los documentos presunta-} mente protegidos por la $L P I$

Si los documentos que queremos utilizar no han sido adquiridos bajo licencia, sino que por ejemplo los hemos localizado por internet sin referencias al respecto o simplemente provienen de la digitalización de un documento en papel, debemos entonces considerar que se encuentran dentro del ámbito de actuación de la $L P I$. Tal y como determina su artículo 10: "1. Son objeto de propiedad intelectual todas las creaciones originales literarias, artísticas o científicas expresadas por cualquier medio o soporte, tangible o intangible, actualmente conocido o que se invente en el futuro". Debemos considerar en sentido amplio el concepto de "obras originales" ya que la ley no nos define el concepto de "originalidad". Solamente, a título de ejemplo, dicho artículo enumera una serie de documentos como libros, folletos, proyectos, etc., aunque, en ningún caso, debemos considerar como restrictiva dicha lista.

Podremos excluir con seguridad de la categoría de documentos protegidos o libres de derechos de explotación aquellos que expresamente la ley así los considera, a saber:

- Obras que no tienen protección (art. 13): "No son objeto de propiedad intelectual las disposiciones legales o reglamentarias y sus correspondientes proyectos, las resoluciones de los órganos jurisdiccionales y los actos, acuerdos, deliberaciones y dictámenes de los organismos públicos, así como las traducciones oficiales de todos los textos anteriores".

- Obras que se encuentran en el dominio público (art. 41): "La extinción de los derechos de explotación de las obras determinará su paso al dominio público. Las obras de dominio público podrán ser utilizadas por cualquiera, siempre que se respete la autoría y la integridad de la obra, en los términos previstos en los apartados 3. y 4. del artículo 14". Es preciso aclarar que las obras que se encuentran en dominio público no es que no gocen de entrada de la protección que les da la ley, sino que los derechos de explotación de las mismas han caducado, aunque siguen vigentes algunos de los derechos morales. Para calcular el paso a dominio público de una obra debemos considerar la fecha de fallecimiento de todos sus autores. De modo general se considera que a partir de los setenta años de la muerte de los mismos (de todos los implicados en el documen-

"Las obras que se encuentran en dominio público no es que no gocen de entrada de la protección que les da la ley, sino que los derechos de explotación de las mismas han caducado" 
to), la obra pasaría a dominio público. Este cálculo es la norma general pero presenta muchas excepciones por lo que es mejor consultar la ley y determinar en cada caso la fórmula a aplicar (Rogel, 2005).

Si efectivamente constatamos que el documento se encuentra protegido por la LPI podemos dar por sentado que necesitaremos la autorización expresa de los titulares de los derechos de explotación de la obra; entendiéndose que es explícita si por ejemplo en una licencia de uso, el licitante permite la incorporación de la obra en una intranet. En el caso de que no la hayamos obtenido a través de una licencia (comercial o gratuita) deberemos contar con la autorización del titular.

\subsection{Excepciones a la norma general}

Decíamos al principio que una de las funciones de la propiedad intelectual es fomentar la creación literaria, artística, científica, etc. Es sabido también que una legislación extremadamente restrictiva podría producir los efectos contrarios al objetivo inicial y por dicho motivo la legislación prevé unos mecanismos compensatorios que permiten el uso restringido de las obras sin autorización en determinadas situaciones. Estas excepciones son bien conocidas por el público en general (derecho a cita, copia privada, copia en bibliotecas y centros similares, etc.).

En el caso que nos ocupa, la comunicación pública de obras en una intranet, no podremos acogernos a las excepciones habituales ya que mayormente dichas excepciones se refieren a la reproducción (fotocopias, digitalizaciones, etc.), mientras que para la comunicación pública (colgar un documento en una red) las excepciones con las que nos encontramos son mínimas.

Solamente en los siguientes casos podremos poner a disposición de los usuarios obras sin autorización de los titulares de los derechos de explotación.

Para referirnos a ellos haremos referencia a la $L P I$ reformada.

\section{Cita e ilustración de la enseñanza}

"1. Es lícita la inclusión en una obra propia de fragmentos de otras ajenas de naturaleza escrita, sonora o audiovisual, así como la de obras aisladas de carácter plástico o fotográfico figurativo, siempre que se trate de obras ya divulgadas y su inclusión se realice a título de cita o para su análisis, comentario o juicio crítico. Tal utilización sólo podrá realizarse con fines docentes o de investigación, en la medida justificada por el fin de esa incorporación e indicando la fuente y el nombre del autor de la obra utilizada.

Las recopilaciones periódicas efectuadas en forma de reseñas o revista de prensa tendrán la consideración de citas. No obstante, cuando se realicen recopilaciones de artículos periodísticos que consistan básica- mente en su mera reproducción y dicha actividad se realice con fines comerciales, el autor que no se haya opuesto expresamente tendrá derecho a percibir una remuneración equitativa. En caso de oposición expresa del autor, dicha actividad no se entenderá amparada por este límite.

2. No necesitará autorización del autor el profesorado de la educación reglada para realizar actos de reproducción, distribución y comunicación pública de pequeños fragmentos de obras o de obras aisladas de carácter plástico o fotográfico figurativo, excluidos los libros de texto y los manuales universitarios, cuando tales actos se hagan únicamente para la ilustración de sus actividades educativas en las aulas, en la medida justificada por la finalidad no comercial perseguida, siempre que se trate de obras ya divulgadas y, salvo en los casos en que resulte imposible, se incluyan el nombre del autor y la fuente.

No se entenderán comprendidas en el párrafo anterior la reproducción, distribución y comunicación pública de compilaciones o agrupaciones de fragmentos de obras o de obras aisladas de carácter plástico o fotográfico figurativo".

De acuerdo pues con la reforma de la LPI que entró en vigor el 19 de julio de 2006, es lícita la comunicación pública de obras (su puesta a disposición en una intranet por ejemplo) en tres casos muy determinados:

a. De manera general si en una obra propia hemos incorporado algún fragmento de una obra ajena y puede considerarse cita. Deja muy claro el articulado correspondiente que solamente pueden ser "fragmentos" o la obra aislada completa en el caso de fotografías o similares. Igualmente, la utilización sin autorización debe de estar justificada por las necesidades de nuestro trabajo docente o de investigación. Es lo que tradicionalmente entendemos por "citar" un documento.

b. Esta reforma de la LPI tenía una cuestión muy candente a tratar. La licitud del uso de las noticias publicadas en periódicos o similares. En un entorno digital y de intranet resulta muy útil para la organización realizar recopilaciones de noticias aparecidas que sean de interés, estén referidas a la misma organización o versen sobre los que la organización trata. La ley no aclara qué es una reseña o revista de prensa, y si bajo dicha excepción pueden efectivamente ampararse este tipo de productos que consisten básicamente en la difusión de un titular con la inclusión del fichero que contiene la noticia. Con la utilización masiva de internet y los servicios de noticias (press clipping) o los periódicos digitales que se nutren de las informaciones de otras fuentes, los editores de los principales medios de comunicación escrita han reivindicado su derecho a ser remunerados por dicha utilización.

La reforma en relación a la $L P I$ actualmente vigente solamente dice al respecto que "cuando se realicen 
recopilaciones de artículos periodísticos que consistan básicamente en su mera reproducción y dicha actividad se realice con fines comerciales, el autor que no se haya opuesto expresamente tendrá derecho a percibir una remuneración equitativa. En caso de oposición expresa del autor, dicha actividad no se entenderá amparada por este límite”. ¿Debemos, por tanto, considerar que la recopilación de noticias que hace una organización sin ánimo de lucro a través de su intranet o web está amparada por el límite? Estamos como antes de la aprobación de la reforma de la ley, el texto enmendado solamente dice cuando no nos encontramos en dicho supuesto, pero no se define cuando estamos en él. Entendemos, y es opinión personal, que si el legislador hubiera querido expresamente excluir también las recopilaciones "sin ánimo de lucro" lo hubiera hecho sin más. Dicha actividad no nos parece que perjudique la explotación normal de la obra ya que estas recopilaciones tienen generalmente un abasto muy limitado (una organización, uno o pocos temas, etc.) y además no generan beneficio económico alguno.

c. El tercer supuesto bajo el que es posible comunicar una obra sin autorización de sus titulares es por mo- tivos de "ilustración de la enseñanza". Esta excepción, nueva en el ordenamiento jurídico español, es el resultado de la transposición del artículo 5.3 a) de la Directiva comunitaria 2001/29/CE que permite introducir una excepción para realizar actos de comunicación pública de obra sin permiso de los titulares de sus derechos de explotación, en beneficio de las actividades de la ilustración con fines educativos o investigación. Desgraciadamente, la polémica por el llamado "canon digital" y el press clipping han eclipsado la introducción y discusión de esta nueva excepción, de vital importancia para favorecer el uso de la tecnología digital en los ámbitos educativos.

La adaptación que el legislador español ha realizado de las posibilidades que permitía la directiva es, a nuestro entender, realmente restrictiva. Para una mejor comprensión de la cuestión, de la transposición de éste y otros artículos que afectan directamente a las bibliotecas, recomendamos la consulta del informe que sobre el tema realizó en su momento el Grupo de Trabajo de Bibliotecas y Propiedad Intelectual de Fesabid ${ }^{7}$. Nosotros nos limitaremos a ofrecer al lector el texto de la directiva y el resultado de la transposición.

\section{Art. 5.3.a) Directiva 2001/29/CE}

3. Los Estados miembros podrán establecer excepciones o limitaciones a los derechos a que se refieren los artículos 2 y 3 en los siguientes casos:

a) cuando el uso tenga únicamente por objeto la ilustración con fines educativos o de investigación científica, siempre que, salvo en los casos en que resulte imposible, se indique la fuente, con inclusión del nombre del autor, y en la medida en que esté justificado por la finalidad no comercial perseguida.

\section{Art. 32. 2 texto LPI reformado}

2. No necesitará autorización del autor el profesorado de la educación reglada para realizar actos de reproducción, distribución y comunicación pública de pequeños fragmentos de obras o de obras aisladas de carácter plástico o fotográfico figurativo, excluidos los libros de texto y los manuales universitarios, cuando tales actos se hagan únicamente para la ilustración de sus actividades educativas en las aulas, en la medida justificada por la finalidad no comercial perseguida, siempre que se trate de obras ya divulgadas y, salvo en los casos en que resulte imposible, se incluyan el nombre del autor y la fuente.

No se entenderán comprendidas en el párrafo anterior la reproducción, distribución y comunicación pública de compilaciones o agrupaciones de fragmentos de obras o de obras aisladas de carácter plástico o fotográfico figurativo.
Es posible constatar como se ha reducido al mínimo posible la excepción prevista por el legislador comunitario. La posibilidad de comunicar públicamente sin autorización una obra para uso docente o de investigación que propugna la directiva se cercena de la siguiente manera:

- Solamente se reconoce el uso "docente" (no el de investigación). ¿Un congreso es una actividad docente?
- Se habla en exclusiva de profesorado (¿quedan pues excluidos los bibliotecarios u otros técnicos que también pueden realizar formación en una organización?).

- Se hace mención a la "educación reglada”, lo que elimina la posibilidad de beneficiarse de la excepción en cursos de formación ocupacional, formación continua, aprendizaje de idiomas "no reglados", etc. 
- Se adjetiva la palabra "fragmentos" con "pequeños", cosa que no se hace en el artículo anterior sobre cita en general.

- A pesar de las limitaciones que ya se introducen, se excluyen expresamente libros de texto y manuales universitarios, obligándonos el legislador en el futuro a realizar continuos ejercicios hermenéuticos para determinar qué es un libro de texto o un manual universitario -que la ley no define-. ¿Todo libro que se titule "manual", lo es? Los bibliotecarios sabemos que no. ¿Cualquier obra citada en una bibliografía docente será "manual"? ¿compendio es sinónimo de "manual"?

- Dichas actividades deberán realizarse "en" las aulas, es decir, se ignora por completo el entorno digital y por consiguiente las aulas "virtuales".

2. Reproducción, préstamo y consulta de obras mediante terminales especializados en determinados establecimientos

En el caso de las bibliotecas y centros similares, además de reconocerse el derecho a reproducir por motivos de investigación como hasta ahora, se ha añadido el supuesto de conservación. La novedad estriba, sin embargo, que la reforma de la LPI permite también la comunicación pública de obras en determinadas circunstancias. A pesar de ello, y como sucedía en el caso anterior, la redacción de la excepción ha reducido al mínimo sus posibilidades. Igualmente en este caso daremos las dos versiones del texto, el comunitario y el estatal:

\section{"En el caso de las bibliotecas y centros similares, además de reconocerse el derecho a reproducir por motivos de investigación como hasta ahora, se ha añadido el supuesto de conservación"}

Si en este caso la directiva comunitaria ya era bastante restrictiva, el legislador español aún ha encontrado hueco para disminuir todavía más su posible aplicación. Es necesario hacer un gran esfuerzo de imaginación para saber cómo se puede aplicar dicha excepción.

En primer lugar, la comunicación pública de obras del fondo de la biblioteca se restringe a usos de investigación, es decir, cuando un estudiante se acerque a dicho documento deberemos desconectar el ordenador ya que uso docente (o estudio personal como lo designa la directiva) podría no ser lo mismo y no está contemplado.

La siguiente cuestión a dilucidar sería determinar qué es una "red cerrada e interna", ¿es la intranet de la biblioteca, de la universidad?, la directiva no hace mención a ninguna arquitectura informática en concreto. Más sugerente resulta todavía la definición la "terminales especializados", término al que también la directiva se refiere. Un ordenador, un PC, ¿es un terminal?, en
Art. 5.3.a) Directiva 2001/29/CE

3. Los Estados miembros podrán establecer excepciones o limitaciones a los derechos a que se refieren los artículos 2 y 3 en los siguientes casos:

$(\ldots)$

n) cuando el uso consista en la comunicación a personas concretas del público o la puesta a su disposición, a efectos de investigación o de estudio personal, a través de terminales especializados instalados en los locales de los establecimientos mencionados en la letra c) del apartado 2 [i. e. bibliotecas, etc.], de obras y prestaciones que figuran en sus colecciones y que no son objeto de condiciones de adquisición o de licencia;

\section{Art. 37.3 texto LPI reformado}

3. No necesitará autorización del autor la comunicación de obras o su puesta a disposición de personas concretas del público a efectos de investigación cuando se realice mediante red cerrada e interna a través de terminales especializados instalados a tal efecto en los locales de los establecimientos citados en el anterior apartado y siempre que tales obras figuren en las colecciones del propio establecimiento y no sean objeto de condiciones de adquisición o de licencia. Todo ello sin perjuicio del derecho del autor a percibir una remuneración equitativa. sentido estricto recibía el nombre de terminal aquella estación de trabajo conectada a un "ordenador central" pero que no poseía disco duro. Además se demanda al "terminal" que sea especializado, lo cual parece que obligue a disponer de "terminales" especializados para esta función. El legislador español pide también que estén "instalados a tal efecto en los locales" lo que parece reforzar la idea de "terminales" con una única función y además se insiste (como en la directiva) en la idea de que estén situados en los "locales" de los estableci- 
mientos. En definitiva, si esta excepción podría haber ayudado a la puesta a disposición de obras de la biblioteca en formato digital a través de la intranet para sus usuarios, su redactado lo excluye. Como mucho podrán habilitarse ordenadores (?) sin acceso a ellos desde fuera de los locales de la biblioteca y para uso solamente de investigadores.

Una vez conseguido esto, el legislador además concluye que "todo ello sin perjuicio del derecho del autor a percibir una remuneración equitativa", lo que quiere decir que para poder dar este mínimo servicio deberá abonarse a los titulares de los derechos de explotación de la obra la correspondiente remuneración.

Es nuestra opinión que para este viaje no hacían falta estas alforjas. Entendemos que si se quería favorecer mínimamente ciertos establecimientos culturales no tiene ningún sentido acabar exigiendo el pago por dicha excepción ya que obligando al pago se equipara a estos establecimientos al régimen general. Es decir, sin esta excepción, bibliotecas y centros similares ya tenían que pagar para realizar actos de comunicación pública. Si se introduce dicha excepción pero fijando remuneración entendemos que se pierde la noción de excepción. Para ser justos, su novedad reside en que los autores no podrán negarse a dicha comunicación pública ya que a tenor del articulado comentado "no necesitará autorización del autor la comunicación de obras o su puesta a disposición...", lo que quiere decir que efectivamente lo podremos hacer, siempre y cuando cumplamos con los requisitos marcados, entre ellos, el pago de una remuneración.

Una solución paralela que ya nos daba la ley sin reformar y que no comporta el pago de ninguna retribución sería la de tener la obra digitalizada en formato cd-rom y servirla a petición al usuario. En este caso no existe comunicación pública, solamente reproducción (la digitalización) y la mera puesta a disposición de las instalaciones para su consulta no constituye un acto de comunicación pública. De hecho la excepción solamente permitiría tener la obra ya instalada en el "terminal".

Lo que se intenta decir es que, aceptando que "terminal" sea algo parecido a un ordenador, el nuevo artículo solamente "ahorraría" al usuario tener que coger el cd-rom e introducirlo en la máquina, ya que se podría tener instalado.

\subsection{Cómo gestionar los derechos de las obras que queremos incorporar en una intranet}

A la vista de todo lo expuesto hasta aquí, el margen de maniobra es muy pequeño. Solamente en contados casos podremos hacer comunicación pública de obras protegidas por la LPI sin autorización de los autores.
"Solamente en contados casos podremos hacer comunicación pública de obras protegidas por la LPI sin autorización de los autores"

Para conseguir el permiso, en el caso de obras "impresas" no adquiridas bajo licencia, deberemos gestionar obra a obra los derechos correspondientes, ya sea contactando con quien sepamos que los tienen (una tarea muy laboriosa) o también gestionando una licencia general con la entidad de gestión adecuada, en este caso Cedro (Centro Español de Derechos Reprográfi$\cos$ ). Desde hace poco, esta entidad ha conseguido la gestión de los derechos de puesta a disposición de la versión digital de muchas obras impresas ${ }^{8}$. La fórmula de la licencia es sencilla, a partir del número de documentos protegidos en nuestra intranet y el número potencial de usuarios se calcula la remuneración anual a satisfacer. Este sistema tienen la ventaja de que con una única gestión y un único pago podemos resolver el problema. Otra cuestión será si el precio resultante puede ser asumido o no por lo que será necesario que en la intranet estén solamente aquellas obras imprescindibles y, por qué no, habilitar solamente el acceso a las personas que realmente las necesiten.

Paralelamente a este sistema, debemos insistir en la necesidad de utilizar obras distribuidas bajo licencia libre, como por ejemplo las de Creative Commons. Actualmente existen diferentes formas de localizarlas en la red ${ }^{9}$; también podemos ayudar al mismo tiempo a su difusión y uso, aplicando licencias copyleft a los documentos de los que nosotros tenemos los derechos de autor.

¿Por qué utilizar el copyleft en obras de nuestra propiedad? En el caso que queramos autorizar de entrada una serie de usos (reproducción, distribución, comunicación pública, etc.) debemos hacerlo expresamente. $\mathrm{Si}$ no lo hacemos así, la futura utilización de la obra por parte de terceros quedaría limitada a lo que marque la LPI (esto es, previa autorización o acogiéndonos a algunas de las excepciones previstas).

Es necesario ser conscientes de que mucha de la documentación que se crea en una organización puede ser "liberada" solamente con la aplicación de una licencia de acceso libre, Creative Commons ${ }^{10}$ o una simple declaración en el mismo documento. Cuesta poco, y los beneficios son muchos, si no tenemos intención de explotar comercialmente la obra. El ejemplo más claro sobre esta liberalización de obras son los depósitos institucionales que algunas instituciones académicas y científicas están desarrollando. 


\section{Protección de datos y derecho a la intimidad}

En la lista $I w e T e l^{11}$ se llevó a cabo un debate sobre el tema de los ficheros de datos de préstamos de los usuarios de las bibliotecas, ¿pueden guardarse los datos de los documentos prestados por un usuario? ¿puede éste negarse a facilitarnos alguno de sus datos personales? Es fácil encontrar en la ficción cinematográfica ejemplos de cómo las datos personales del uso de las bibliotecas se utilizan en investigaciones criminales. En Todos los hombres del presidente (1976), uno de los periodistas que está investigando el llamado Watergate llama ni más ni menos que a la Library of Congress para saber a qué libros ha accedido un congresista implicado en la trama. Dicha información se la facilitan ¡por teléfono! Otro ejemplo del celuloide lo encontramos en Seven (1995), película en la que los agentes responsables de la localización de un sociópata se hacen con los datos de préstamos de obras "satánicas" con el fin de localizar al criminal.

Naturalmente, la realidad siempre supera a la ficción y los ficheros de préstamo de las bibliotecas y los listados de compras de las librerías se han convertido, Patriot USA Act mediante, en fuente de información de supuesta vital importancia en los EUA para la investigación del terrorismo (Bowers, 2006). Estos ejemplos poden de manifiesto la actualidad de la cuestión de la protección de los datos personales y la sensibilidad que despierta su recogida, tratamiento y difusión en las organizaciones.

¿Hasta qué punto una universidad puede hacer público el directorio de su personal en su web sin el permiso expreso de sus trabajadores? ¿es lo mismo si estos datos de ofrecen solamente en la intranet?

De entrada podemos afirmar que, así como en temas de propiedad intelectual no existían grandes diferencias entre documentos alojados en web o en intranet, en la protección de datos personales sí que tenemos qué considerar en qué entorno se están haciendo accesibles datos considerados personales. Veremos posteriormente que, efectivamente, no es lo mismo ofrecer acceso a datos personales a usuarios de una intranet que al público en general a través de una web.

Igualmente, si bien podríamos encontrar organizaciones que no necesitan gestionar los derechos de au-

\footnotetext{
"No es lo mismo ofrecer acceso a datos personales a usuarios de una intranet que al público en general a través de una web"
}

tor de los documentos de su intranet dado que no están protegidos por la ley, se nos hace más difícil imaginar una institución de cierta complejidad que no disponga de ficheros de datos personales. Las bibliotecas recogen datos de préstamo, de consulta de documentos especiales (tesis, etc.), de acceso a internet, etc., pero la lista se hace casi infinita al considerar el resto de organizaciones. Al visitar una web se suelen recoger datos de acceso, se dispone de información de los trabajadores de una organización, de las compras, las ventas, personas de contacto. Además, algunas organizaciones documentales, como podrían ser los archivos de los hospitales, custodian uno de los datos más sensibles definidos por ley, los referidos a la salud incluidos en las historias clínicas.

Si a esto añadimos el hecho de que en España tenemos una de las leyes más duras, en los que a sanciones se refiere ${ }^{12}$, deberemos extremar el celo al realizar las pertinentes auditorias a fin de garantizar el adecuado tratamiento de los datos personales que hayamos recogido. Frecuentemente, estos datos se hacen accesibles a través de las intranets de las organizaciones, por lo que será necesario disponer de los protocolos de trabajo adecuados para garantizar su licitud.

\subsection{Datos personales sujetos a protección}

La ley, de entrada, no determina expresamente qué datos debemos recoger y cuáles no, y mucho menos impide que se recojan datos personales en general. Así, en el ejemplo de los préstamos públicos a que hacíamos referencia anteriormente, existe una cierta "leyenda urbana" que explica que no se pueden guardar los ficheros de préstamo de las bibliotecas porque la ley lo impide. Formulado en estos términos podemos diferir de dicha aseveración dado que nada en la ley impide a las bibliotecas recoger estos datos. Ahora bien, ya que efectivamente son datos personales, la ley sí marca qué, cómo y hasta cuándo podemos gestionarlos.

Debemos señalar que la ley no solamente es aplicable a los datos gestionados informáticamente, sino que también debe observarse para los personales recogidos o conservados exclusivamente en soporte papel (López-Vidriero, 2005). Así, el artículo 2.1. de la $L O P D$ delimita su ámbito de aplicación a: “...los datos de carácter personal registrados en soporte físico, que los haga susceptibles de tratamiento, y a toda modalidad de uso posterior de estos datos por los sectores público y privado". Como puede observarse se hace referencia a datos organizados almacenados en soporte físico; un listado en papel o una carpeta lo son.

Paralelamente, la ley define en su artículo tercero una serie de conceptos necesarios para una correcta aplicación, entre los que destacamos: 


\begin{tabular}{|l|l|}
\hline Art. 3 & Definición \\
\hline Datos de carácter personal & $\begin{array}{l}\text { Cualquier información concerniente a personas físicas identificadas o } \\
\text { identificables. }\end{array}$ \\
\hline Fichero & $\begin{array}{l}\text { Todo conjunto organizado de datos de carácter personal, cualquiera que } \\
\text { fuere la forma o modalidad de su creación, almacenamiento, organiza- } \\
\text { ción y acceso. }\end{array}$ \\
\hline Tratamiento de datos & $\begin{array}{l}\text { Operaciones y procedimientos técnicos de carácter automatizado o no, } \\
\text { que permitan la recogida, grabación, conservación, elaboración, modifi- } \\
\text { cación, bloqueo y cancelación, así como las cesiones de datos que resul- } \\
\text { ten de comunicaciones, consultas, interconexiones y transferencias. }\end{array}$ \\
\hline $\begin{array}{l}\text { Responsable del fichero o trata- } \\
\text { miento }\end{array}$ & $\begin{array}{l}\text { Persona física o jurídica, de naturaleza pública o privada, u órgano ad- } \\
\text { ministrativo, que decida sobre la finalidad, contenido y uso del trata- } \\
\text { miento. }\end{array}$ \\
\hline Afectado o interesado & $\begin{array}{l}\text { Persona física titular de los datos que sean objeto del tratamiento a que } \\
\text { se refiere el apartado c) del presente artículo. }\end{array}$ \\
\hline Cesión o comunicación de datos & Toda revelación de datos realizada a una persona distinta del interesado. \\
\hline Consentimiento del interesado & $\begin{array}{l}\text { Toda manifestación de voluntad, libre, inequívoca, específica e infor- } \\
\text { mada, mediante la que el interesado consienta el tratamiento de datos } \\
\text { personales que le conciernen. }\end{array}$ \\
\hline Fuentes accesibles al público & $\begin{array}{l}\text { Aquellos ficheros cuya consulta puede ser realizada, por cualquier per- } \\
\text { sona, no impedida por una norma limitativa o sin más exigencia que, en } \\
\text { su caso, el abono de una contraprestación. }\end{array}$ \\
\hline
\end{tabular}

A partir de estas consideraciones podemos realizar las siguientes observaciones:

- Los datos protegidos tienen que hacer referencia a personas físicas. Dicho de otra forma, no se regirán por la $L O P D$ los datos referidos exclusivamente a personas jurídicas. A modo de ejemplo, el fichero con los datos de los clientes de una empresa no estaría incluido al contener solamente informaciones pertenecientes a personas jurídicas. Deberemos sin embargo considerar la posibilidad que entre nuestros clientes encontremos personas físicas, por ejemplo trabajadores autónomos. En este caso los datos sí que quedarían incluidos en la categoría de protegidos. Igualmente si entre la información concerniente a una empresa (denominación social, razón social, teléfono, etc.) se incluyera el nombre de la persona de contacto de la misma, también debería de ser protegida automáticamente. Tanto en uno u otro caso nos encontraríamos ante la posibilidad de personas identificadas (fehacientemente) o identificables (en potencia).

- El concepto de fichero tiene un amplio alcance. Si en la anterior Ley 5/1992 de protección de datos, ahora derogada, se hacía especial mención a ficheros automatizados (art. 3.b), la vigente $L O P D$ solamente se refiere a fichero como forma de organización de datos, pero sin limitarse al ámbito digital. Así pues, un listado en el que los usuarios de una biblioteca deben registrarse para poder acceder a un ordenador también tendría la consideración de fichero de datos personales (dado que el usuario es una persona física).
- En la enumeración de los diferentes tratamientos a los que podemos someter los datos personales queda otra vez patente la no exclusividad del tratamiento informático. Es decir, el tratamiento podrá ser informático, o no, solamente se precisa que los datos puedan ser grabados (en papel por ejemplo) para considerar que ya los estamos manejando.

- Se introduce en la ley la necesaria existencia de un responsable de los ficheros (informáticos o no) que podrá ser una persona física o jurídica y que será la responsable del cumplimento de todos los requisitos que marca la ley. Es importante que las organizaciones presenten cuántos ficheros susceptibles de incluir datos personales manejan sus colaboradores ya que serán ellas las responsables ante la ley.

- Cualquier puesta a disposición de terceros de datos personales es una "cesión o comunicación de datos". Con dicho concepto se definirá cualquier acceso que se realice por terceras personas a los ficheros de datos personales y que puede ser físico (consulta de un listado) o virtual (a través de la intranet, de un PC local, de una página, web, etc.). Debemos entender por cesión cualquier revelación que hagamos de datos personales independientemente del medio (de forma oral, escrita, entre ordenadores, etc.). Todos recordamos la época en que los centros escolares exponían los listados de notas en los tablones de anuncios incluyendo el nombre, apellido o sencillamente se leían en clase los resultados de un examen. La nota de un estudiante es un dato de ca- 
rácter personal -“cualquier información concerniente a personas físicas identificadas o identificables", art. 3.a., (Apdcm, 2005)- del que se está haciendo una "cesión o comunicación de datos". Igualmente, también lo es permitir el acceso al directorio de la empresa en una web o una intranet.

\subsection{Principios para la recogida y gestión de da- tos personales}

Al tratar la cuestión de la propiedad intelectual acudíamos al concepto de equilibrio entre el derecho de los autores a su obra y el del acceso a la cultura de todos los ciudadanos. De igual forma, al hablar de protección de datos cabe establecer un equilibrio "entre la sociedad de la información y las libertades de los ciudadanos" (Herrán, 2001). Es obvio que las organizaciones necesitan datos personales para su normal funcionamiento, por ejemplo ¿cómo realizar préstamos de documentos si no podemos anotar quién se lleva una obra? De este modo, la $L O P D$ establece una serie de principios en el momento de su recogida y tratamiento cuya filosofía se podría resumir en el "mínimo de datos necesarios" y el máximo posible de protección. En palabras de Asís Roig (2002) podemos considerar que toda la legislación de protección de datos personales tiene como base el "principio de precaución", es decir, las medidas señaladas en la ley intentan directamente prevenir un mal uso de los datos personales. Es desde esta perspectiva preventiva bajo la que consideramos que es necesario trabajar.

Los principios que rigen la gestión de los datos personales son los siguientes:

- Calidad de los datos (art. 4).

- Derecho de información en su recogida (art. 5).

- Consentimiento del afectado (art. 6) y datos especialmente protegidos (art. 7).

- Seguridad de los datos (art. 9).

\subsubsection{Principio de calidad de los datos}

Vendrá determinada por:

- La idoneidad de la información recogida.

- La veracidad.

- El tiempo de almacenamiento.

- La forma en cómo se recojan.

\section{¿Qué datos podemos recoger?}

El artículo 4.1 de la $L O P D$ estipula que: "Los datos de carácter personal sólo se podrán recoger para su tratamiento, así como someterlos a dicho tratamiento, cuando sean adecuados, pertinentes y no excesivos en relación con el ámbito y las finalidades determinadas, explícitas y legítimas para las que se hayan obtenido".
El hecho de que los datos sean "adecuados", término demasiado impreciso, pretende reducir al mínimo posible necesario los que se estén recogiendo. Los que solicitemos deben de ser lógicamente necesarios para el objetivo que nos hemos propuesto, y solamente para eso. Así por ejemplo, en un formulario que tengamos en nuestra web para que un cliente o usuario reciba un boletín electrónico de novedades parece lógico solicitar el correo-e. Sería más difícil de considerar la obligación de hacerle facilitar su dirección postal dado que el objetivo es la difusión de un boletín electrónico. Lo más sensato en estos casos es partir del principio que cuantos menos datos solicitemos mejor.

Otra cuestión a dilucidar es hasta qué punto podemos utilizar los datos recogidos inicialmente para una finalidad determinada, con el objetivo de usarlos para una función distinta. Sería el caso del fichero de datos personales de los usuarios de un servicio determinado: podrían ser utilizados para ofertar otro. Esta cuestión no es menor y generó una considerable polémica en el trámite de aprobación de la ley (Herrán, 2002). El art. 4.2 determina que "los datos de carácter personal objeto de tratamiento no podrán usarse para finalidades incompatibles con aquellas para las que los datos hubieran sido recogidos". Nótese que se utiliza el término "finalidades incompatibles" y no "finalidades distintas" con lo que el legislador quiso no restringir totalmente la reutilización de datos, asumiendo en todo caso, suponemos, el riesgo de la imprecisión de la definición. ¿qué debemos considerar por "finalidades incompatibles"?

Desde la óptica del principio de precaución al que nos referíamos al principio se nos antoja que debemos ser estrictos en restringir al máximo la consideración de finalidades compatibles. Siguiendo con en el ejemplo que citábamos de la difusión de un boletín electrónico, los datos fueron recogidos para esa función; solamente deberíamos considerarlos compatibles para ello, servicios exactamente similares o que substituyan, amplíen o mejoren esta actividad inicial. Imaginemos una biblioteca que dispone de los datos personales de lectores del servicio de préstamo y se plantea si pueden ser utilizados para remitir electrónicamente un boletín de novedades de nueva realización. Pensamos que no sería adecuado utilizarlos automáticamente sin antes pedir la conformidad de los usuarios inscritos dado que la recogida de datos tenía exclusivamente como misión la utilización del servicio de préstamo. Sí pensamos que sería más adecuado remitirles un correo electrónico informándoles del nuevo servicio y de la posibilidad de autorizar la inclusión de sus datos en la base de datos de los receptores del boletín de novedades.

Este mismo artículo nos aclara que los datos recogidos sí que pueden ser utilizados a efectos de estudios históricos, estadísticos o científicos. Aceptando, en 
todo caso, que se realizan por el mismo servicio que lo lleva a cabo.

\section{¿Debemos actualizar los datos?}

Una función del responsable del fichero de datos personales es mantenerlo actualizado de forma que la información personal almacenada sea cierta. El art. 4.3 subraya que "los datos de carácter personal serán exactos y puestos al día de forma que respondan con veracidad a la situación actual del afectado". Aparte del hecho que se supone que la organización es la primera interesada en mantener al día los registros de sus bases de datos, debemos recordar que los afectados tienen derecho a conocer qué informaciones tenemos sobre ellos $\mathrm{y}$, en todo caso, exigirnos la rectificación de todo lo que no se corresponda con la realidad (art. 4.4).

"Ios afectados tienen derecho a conocer qué informaciones tenemos sobre ellos $y$, en todo caso, exigirnos la rectificación de todo lo que no se corresponda con la realidad"

\section{¿Cuánto tiempo debemos guardar los datos?}

El período durante el que debemos conservar los ficheros de datos personales es una cuestión que deben tener muy en cuenta los responsables del sistema de información de la organización. Dicho aspecto queda relacionado, en términos documentales, a la gestión general de la documentación de las organizaciones. Es conocido que los sistemas archivísticos prevén unas tablas de conservación y eliminación de documentos que tienen como función gestionar el destino final de los materiales almacenados. En el momento de determinar los plazos de eliminación deberemos tener muy en cuenta la $L O P D$ para conservarlos como mínimo, durante el tiempo que se deriva de la aplicación de la ley.

Este concepto es aplicable igualmente a los ficheros de datos personales de nuestra organización. A tenor de lo que expresa el art. 4.5 "los datos de carácter personal serán cancelados cuando hayan dejado de ser necesarios o pertinentes para la finalidad para la cual hubieran sido recabados o registrados. No serán conservados en forma que permita la identificación del interesado durante un período superior al necesario para los fines en base a los cuales hubieran sido recabados o registrados".

El principio general será pues, que los datos personales solamente se guardarán mientras esté vigente la función para la que fueron recogidos. En caso contrario deberán ser cancelados (art. 16.3): "la cancelación dará lugar al bloqueo de los datos, conservándose únicamente a disposición de las Administraciones públicas, Jueces y Tribunales, para la atención de las posibles responsabilidades nacidas del tratamiento, durante el plazo de prescripción de éstas. Cumplido el citado plazo deberá procederse a la supresión".

Así pues debemos distinguir entre cancelación/bloqueo de los datos y eliminación definitiva del registro. En el primer caso se impide la utilización de dicha información para el uso que habíamos previsto, mientras que la eliminación incluye su destrucción física.

A efectos de la correcta gestión de la protección de datos personales, el sistema de gestión documental de la organización deberá determinar en qué momento podemos eliminar físicamente los datos de un fichero en concreto. La $L O P D$ no marca un plazo determinado: "los datos de carácter personal deberán ser conservados durante los plazos previstos en las disposiciones aplicables o, en su caso, en las relaciones contractuales entre la persona o entidad responsable del tratamiento y el interesado" (art. 16.5). Debemos entender por "disposiciones aplicables" la legislación que regula los períodos de conservación de la documentación en general, incluida, la misma LOPD (Quinto, 2006). A falta de un plazo concreto, intentaremos calcular el tiempo mínimo y máximo durante el cual podemos (o debemos) conservar los ficheros de datos personales no utilizados:

- Mínimo. Decíamos que la $L O P D$ no fija un plazo concreto a partir del que podamos eliminar efectivamente cualquier tipo de dato. Esto es debido al hecho de que ya existe o podría legislarse en el futuro un plazo de conservación específico en función del tipo de dato (por ejemplo, los relativos a la salud). A pesar de ello podemos fijar en tres años el período mínimo de conservación de cualquier tipo de datos personal. El cómputo es el resultado de observar el artículo 47 de la misma ley referente a la prescripción de las posibles infracciones; aquellas de carácter leve prescriben al año, las graves a los dos, mientras que las muy graves lo hacen a los tres. En todos los casos a partir de la fecha de la comisión de la presunta infracción. Dicho de otra forma, durante un plazo máximo de tres años a partir de su creación, modificación u otro proceso (en el cupiera infringir la legislación) nos podríamos encontrar con la apertura de un procedimiento de infracción por lo que es aconsejable conservar los datos como mínimo durante ese período.

- Máximo. No viene marcado en la $L O P D$, solamente se prescribe que "los datos de carácter personal serán cancelados cuando hayan dejado de ser necesarios o pertinentes para la finalidad para la cual hubieran sido recabados o registrados. No serán conservados en 
forma que permita la identificación del interesado durante un período superior al necesario para los fines en base a los cuales hubieran sido recabados o registrados." (art. 4.5). Así pues no parece que una conservación indefinida sin justificación sea adecuada a tenor de este artículo. Deberemos en cada caso decidir durante cuánto como máximo conservaremos los datos personales que ya no se utilizan.

Debemos insistir nuevamente en la necesidad de estudiar si los datos personales que almacenamos se encuentran regulados por alguna normativa específica diferente de la $L O P D$, ya que en este caso el tiempo mínimo de conservación podría ser superior. Es lo que ocurre con las historias clínicas, datos contables ( i contienen datos personales), expedientes administrativos, etc. (Quinto, 2006), donde debemos sumar la legislación autonómica si la naturaleza del dato entrar dentro de sus competencias.

\subsubsection{Principio de información en la recogida de los datos}

El responsable del fichero tiene el deber de informar a la persona afectada del hecho que sus datos serán recogidos en un fichero. Esta obligación es una de las bases que permiten ejercer de forma efectiva los derechos de los afectados (López-Vidriero, 2005). Estas informaciones, que deben aparecer en los formularios de recogida de información, se regulan a través del artículo $5^{\circ}$ de la $L O P D$ y serán comunicados de forma expresa, precisa e inequívoca (art. 5.1). Analizando solamente el primer epígrafe del artículo 5 de la $L O P D$, básicamente indicamos:

- De la existencia de un fichero o tratamiento de datos de carácter personal, de la finalidad de la recogida de éstos y de los destinatarios de la información.

- Del carácter obligatorio o facultativo de su respuesta a las preguntas que les sean planteadas.

- De las consecuencias de la obtención de los datos o de la negativa a suministrarlos.

- De la posibilidad de ejercitar los derechos de acceso, rectificación, cancelación y oposición.

- De la identidad y dirección del responsable del tratamiento o, en su caso, de su representante. Cuando no esté establecido en el territorio de la Unión Europea y utilice en el tratamiento de datos medios situados en territorio español, deberá designar, salvo que tales medios se utilicen con fines de trámite, un representante en España, sin perjuicio de las acciones que pudieran emprenderse contra el propio responsable del tratamiento.

Cabe señalar que la recogida de datos no será lícita si no se cumplen las condiciones de este artículo. Se prevén, igualmente una serie de excepciones a la norma general en los casos de que el objetivo de la recogida haga obvia la justificación del dato (art. 5.3) o los datos no hayan sido facilitados por el propio afectado (art. 5.4 y 5.5$)$.

\subsubsection{Principio del consentimiento informado}

La norma general es clara, cualquier tratamiento de los datos personales debe de contar con el consentimiento expreso del afectado: "el tratamiento de los datos de carácter personal requerirá el consentimiento inequívoco del afectado, salvo que la ley disponga otra cosa" (art. 6.1). Como se define en el art. 3.h. de la $\angle O P D$, entenderemos por "consentimiento del interesado" "toda manifestación de voluntad, libre, inequívoca, específica e informada, mediante la que el interesado consienta el tratamiento de datos personales que le conciernen".

Esta norma general es lo que posibilita la llamada autodeterminación informativa de la ciudadanía, es el ciudadano quien tiene el control de sus datos (Apdcm, 200?).

Así pues, en los textos informativos anexos a los formularios de recogida de datos personales (en papel o web) deberemos añadir una mención expresa conforme se autoriza a la organización al tratamiento de los datos.

La ley prevé igualmente una serie de excepciones en lo que respecta al consentimiento informado; no será necesario cuando: "los datos de carácter personal se recojan para el ejercicio de las funciones propias de las Administraciones públicas en el ámbito de sus competencias; cuando se refieran a las partes de un contrato o precontrato de una relación negocial, laboral o administrativa y sean necesarios para su mantenimiento o cumplimiento; cuando el tratamiento de los datos tenga por finalidad proteger un interés vital del interesado en los términos del artículo 7, apartado 6, de la presente ley, o cuando los datos figuren en fuentes accesibles al público y su tratamiento sea necesario para la satisfacción del interés legítimo perseguido por el responsable del fichero o por el del tercero a quien se comuniquen los datos, siempre que no se vulneren los derechos y libertades fundamentales del interesado" (art. 6.2).

\subsubsection{Datos especialmente protegidos}

En consonancia con el apartado 2 del artículo 16 de la Constitución, la $L O P D$ enumera una serie de tipos de datos que son especialmente sensibles y sobre los que no se puede obligar a nadie a facilitarlos. Se entenderá por datos especialmente protegidos aquellos que hagan referencia a la ideología, la afiliación sindical, la religión o creencias, el origen racial, la salud y la vida sexual de las personas. No todos ellos tienen el mismo 
nivel de legislación ya que la $L O P D$ viene a establecer datos especialmente protegidos de primer y segundo grado (Conde, 2006). Alguno autores llegan a hablar de hasta tres tipos (Toniatti, 1991).
Dado que la lectura del artículo 7 se nos antoja poco didáctica, para la mejor comprensión de los distintos aspectos que regulan los datos especialmente protegidos, ofrecemos la siguiente tabla:

\begin{tabular}{|c|c|c|c|c|}
\hline Tipo de dato & $\begin{array}{l}\text { Se impide } \\
\text { obligar al } \\
\text { afectado a } \\
\text { facilitarlo } \\
\text { (art. 7.1) }\end{array}$ & $\begin{array}{l}\text { Consentimiento } \\
\text { expreso y por } \\
\text { escrito } \\
\text { (art. 7.2) }\end{array}$ & $\begin{array}{l}\text { Consentimiento } \\
\text { expreso o ley } \\
\text { que lo permita } \\
\text { (art. } 7.3)^{\mathrm{iii}}\end{array}$ & $\begin{array}{l}\text { Prohibición de } \\
\text { disponer de } \\
\text { ficheros creados } \\
\text { con esta única } \\
\quad \text { finalidad } \\
\quad(\text { art. } 7.4)^{\text {iv }}\end{array}$ \\
\hline Ideología & $\mathrm{X}$ & $x$ & & $x$ \\
\hline Religión & $x$ & $x$ & & $x$ \\
\hline Creencias & $x$ & $x$ & & $x$ \\
\hline Afiliación sindical & & $x$ & & $X$ \\
\hline Origen racial o étnico $v$ & & & $x$ & $x$ \\
\hline \multirow[t]{2}{*}{ Salud } & & & $x$ & \\
\hline & \multicolumn{4}{|c|}{$\begin{array}{l}\text { Sin perjuicio de lo que se dispone en el artículo } 11 \text { respecto de la cesión, las } \\
\text { instituciones y los centros sanitarios públicos y privados y los profesionales } \\
\text { correspondientes podrán proceder al tratamiento de los datos de carácter } \\
\text { personal relativos a la salud de las personas que a ellos acudan o hayan de } \\
\text { ser tratados en los mismos, de acuerdo con lo dispuesto en la legislación es- } \\
\text { tatal o autonómica sobre sanidad (art. } 7.8 \text { ). }\end{array}$} \\
\hline Vida sexual & & & $x$ & $x$ \\
\hline \multicolumn{5}{|c|}{$\begin{array}{l}\text { En todos los supuestos anteriores podrán ser objeto de tratamiento los datos de carácter personal } \\
\text { (...), cuando dicho tratamiento resulte necesario para la prevención o para el diagnóstico médicos, la } \\
\text { prestación de asistencia sanitaria o tratamientos médicos o la gestión de servicios sanitarios, siempre } \\
\text { que dicho tratamiento de datos se realice por un profesional sanitario sujeto al secreto profesional o } \\
\text { por otra persona sujeta asimismo a una obligación equivalente de secreto. También podrán ser objeto } \\
\text { de tratamiento los datos a que se refiere el párrafo anterior cuando el tratamiento sea necesario para } \\
\text { salvaguardar el interés vital del afectado o de otra persona, en el supuesto de que el afectado esté } \\
\text { física o jurídicamente incapacitado para dar su consentimiento (art. 7.6). }\end{array}$} \\
\hline $\begin{array}{l}\text { Comisión de } \\
\text { infracciones penales } \\
\text { o administrativas }\end{array}$ & \multicolumn{4}{|c|}{$\begin{array}{l}\text { Solamente se incluirán dichos datos en los ficheros de las administraciones } \\
\text { públicas en los casos marcados por la normas reguladoras correspondientes } \\
\text { (art. 7.5). }\end{array}$} \\
\hline
\end{tabular}

i. En el caso de recabarse estos datos se informará al afectado de su derecho a no facilitar dicha información.

ii. A excepción de los datos obrantes en manos de partidos políticos, sindicatos, iglesias, confesiones o comunidades religiosas y asociaciones, fundaciones y otras entidades sin ánimo de lucro, cuya finalidad sea política, filosófica, religiosa o sindical. Para la cesión de dichos datos sí que será necesario el consentimiento.

iii. Nótese que solamente se requiere el consentimiento expreso (no exige que sea por escrito).

iv. Nótese que lo ilícito sería la creación del fichero si no se cumpliera que su finalidad respondiera al interés general, a lo dictaminado en una ley o disponer de como mínimo del consentimiento del afectado (Battaner, 2006) ${ }^{13}$.

v. No se consideraría dato especialmente protegido la nacionalidad.

Muchos profesionales de la información pueden gestionar en sus intranets datos personales que podrían asimilarse a alguna de estas categorías, es el caso de los expedientes de bajas laborales por enfermedades, incapacidades temporales o permanentes, afiliación sindical a efectos del pago de la correspondiente cuota, etc.

Igualmente, algunos centros documentales como bibliotecas, archivos o centros de documentación po- drían querer ofrecer servicios a grupos concretos de usuarios con necesidades específicas como inmigrantes, personas con movilidad reducida, problemas de visión, colectivos religiosos concretos, etc. Para hacer llegar estos servicios sería necesario recabar datos especialmente protegidos, por lo que en todo caso es conveniente primero realizar un estudio de las características de los mismos y las condiciones bajo las cuales dicha información puede ser tratada. 


\subsubsection{Principio de la seguridad de los datos}

Una vez que se han cumplido con todos los requisitos necesarios para recopilar y tratar datos personales, el responsable del fichero tiene la obligación de garantizar su seguridad. En este sentido, la $L O P D$ obliga a aplicar una serie de medidas tendentes a garantizar que nadie podrá acceder a los datos personales que tenemos custodiados a no ser que sea en cumplimiento de lo marca la ley (art. 9.1). Es más, se impide expresamente disponer de datos personales si no somos capaces de garantizar los niveles de seguridad exigidos (art. 9.2).

\section{"Se impide expresamente disponer de datos personales si no somos capaces de garantizar los niveles de seguridad exigidos"}

Recientemente hemos podido asistir a la polémica generada por el hecho que la Dirección General de Tráfico permitía el acceso a los conductores a sus expedientes personales para consultar el saldo de los puntos de su carnet de conducir. Al parecer las medidas de seguridad previstas (DNI y fecha de expedición del mismo) resultaban insuficientes al no exigirse además una clave personalizada.

La normativa que regula las condiciones de seguridad a aplicar en ficheros de datos personales se encuentra en el Real Decreto 994/1999, de 11 de junio, por el que se aprueba el Reglamento de medidas de seguridad de los ficheros automatizados que contengan datos de carácter personal. Dicho decreto, anterior a la $L O P D$, formaba parte del desarrollo de la anterior ley de protección de datos Lortad.

Los requerimientos de seguridad del Real Decreto 994/1999 se basan en la definición de tres niveles de seguridad (bajo, medio y alto). Cada uno conlleva la aplicación de una serie de medidas concretas como pueden ser la elaboración de un protocolo de seguridad, la creación de un registro de incidencias, control de los accesos (virtuales o físicos, etc.).

En función del tipo de datos personales que contenga el fichero deberemos ir acumulando las medidas de protección que se apliquen. Así, todos los ficheros con datos personales deberán cumplir las medidas de seguridad del nivel básico. Si los datos personales son "relativos a la comisión de infracciones administrativas o penales, Hacienda Pública, servicios financieros (...)" (art. 4.2. RD 994/1999), a las medidas de seguridad del nivel básico deberemos sumar las del nivel medio. Fi- nalmente, en el caso de los datos personales especialmente protegidos deberemos también sumar las medidas de seguridad del nivel alto.

\subsection{Comunicación de datos personales}

Recordemos que por comunicación (o cesión) de datos personales entenderemos: "toda revelación de datos realizada a una persona distinta del interesado" (art. 3.i LOPD). Así pues, entra dentro de esta categoría permitir el acceso en cualquier forma (personalmente, por teléfono, a través de intranet o web, etc.) a otras personas que no sean el usuario.

En el entorno de una intranet es frecuente dar acceso a los miembros de la organización a ficheros que pueden contener datos personales (directorios, nóminas, curricula, etc.). ¿Estamos en este caso también haciendo una comunicación de datos? ¿podemos dar acceso universal a ficheros con datos personales a todos los miembros de la organización? De manera general no. Recordemos que el principio de calidad de recogida de datos personales (art. 4.1) restringía el tratamiento al "ámbito y finalidades determinadas". Así pues, solamente aquellas personas relacionadas directamente con la función concreta para la que se han recogido los datos podrán acceder a ellos. Podríamos ejemplificarlo con el supuesto ya comentado del fichero de préstamos de obras. Entendemos que solamente las personas asignadas al servicio deberían poder acceder a esa información ya que les es necesaria para el desarrollo de sus funciones.

Aclarado este punto, como principio general deberemos observar que ninguna comunicación o cesión de datos personales está autorizada sin previo consentimiento del afectado (art. 11.1) a excepción de los supuestos contemplados en el art. 11.2, entre los que destacamos que así lo marque una ley, sean datos de fuentes accesibles al público (definidas en el art. 3.j) o cuando dicha comunicación sea necesaria para el ejercicio de una relación jurídica aceptada previamente (cuando realizamos un pedido y el proveedor facilita al transportista externo nuestros datos personales para la entrega de la mercancía).

Igualmente deberemos analizar si la comunicación de datos personales de índole laboral a través del web cumple con las normas previstas (un ejemplo sería el de los directorios de empresas e instituciones). Nadie duda de la utilidad que reporta al cliente o usuario poder localizar a través del directorio institucional al responsable de un determinado servicio. Ahora bien, teniendo en cuenta que un directorio de personal se identifica a una persona, estamos delante de una comunicación de datos de carácter personal; a todos los efectos, la dirección de correo electrónico (aunque tenga formato institucional) se considera dato personal $(A E P D, 1999)$. 
El principio general es claro, debemos contar con la autorización de la persona en cuestión para hacer público su nombre y dirección de correo electrónico. Otra cosa sería que dicha información se facilitara en un entorno de intranet o solamente a los clientes o usuarios interesados en un servicio ejecutado por esa persona (Apdcm, 2005).

\subsection{Registro de ficheros}

De manera sucinta solamente haremos referencia a la necesidad de registrar cualquier fichero que contenga datos personales. Los ficheros de titularidad privada (empresas, etc.) deben hacerlo a través de la Agencia Española de Protección de Datos ${ }^{14}$, mientras que las administraciones públicas podrán hacerlo en esta misma agencia o a través de las agencias de protección de datos autonómicas existentes ${ }^{15}$ (es el caso de la Comunidad de Madrid, Euskadi y Catalunya). En cuanto a los ficheros de titularidad pública, igualmente deberá publicitarse su existencia a través del $B O E$ o diario oficial autonómico correspondiente.

\section{Conclusiones}

Desde una óptica general y sin analizar casos concretos hemos querido ofrecer una panorámica general de dos aspectos que se nos antojan de especial importancia para la correcta gestión de la información contenida en una intranet. Protección de datos y propiedad intelectual son parte del complejo mundo jurídico que la automatización de la gestión de la información ha situado en el primer plano de la actualidad profesional.

Los principios que rigen una y otra temática jurídica son diferentes y autónomos, pero confluyen por igual en los diferentes procesos de recogida y difusión de la información en las intranets y otras plataformas similares de gestión de información.

El principio de la propiedad intelectual es claro: ningún acto de comunicación pública de obras protegidas puede llevarse a cabo sin autorización de los titulares de los derechos de explotación de la obra. Esta prohibición conlleva igualmente una serie de excepciones que hemos ido estudiando y que en todo caso deberán aplicarse al caso particular de cada organización.

Paralelamente, la protección de datos personales pretende preservar la intimidad de todos nosotros y nos permite tener el control total sobre nuestros datos más íntimos. La ley marca un camino a seguir para poder gestionar los datos que necesitemos de nuestros clientes y usuarios con el fin de hacer compatible el derecho de unos a su intimidad y la necesidad de las organizaciones a disponer de los datos necesarios para ejercer sus finalidades.

Hemos reivindicado, y volvemos a insistir en ello, el importante papel que los profesionales de la infor- mación pueden realizar en este ámbito frecuentemente descuidado en las organizaciones.

\section{Notas}

1. Este servicio ofrece a sus usuarios diferentes prestaciones relacionadas con el derecho de autor entre las que se encuentra la de facilitar una información básica sobre dicha temática. http://bibliotecnica.upc.edu/sepi.asp

2. Aunque formalmente "propiedad intelectual" incluye tanto el derecho de autor como la propiedad industrial (patentes, marcas, etc.), en España se suelen usar como sinónimos propiedad intelectual y derecho de autor. De hecho la ley de derechos de autor española lleva por título "Ley de propiedad intelectual".

3. http://eprints.rclis.org/view/subjects/ED.html

4. Paralelamente, las comunidades autónomas pueden ejercer algunas competencias ejecutivas en esta materia.

5. http://www.constitucioneuropea.es/pdf/ConstitucionEuropea.pdf

6. Igualmente puede ser de utilidad consultar la web del Grupo de Biblioteca y Propiedad Intelectual de Fesabid y el Servicio de Propiedad Intelectual de la Universitat Politècnica de Catalunya.

http://www.fesabid.org/federacion/gtrabajo/bpi/document.htm

http://bibliotecnica.upc.es/sepi/

7. http://www.fesabid.org/federacion/gtrabajo/bpi/alegacionesfesabidseptiembre2005.pdf

8. http://www.cedro.org/vLeerNoticia2.asp? Ide $=1577$

9. En esta dirección se ofrece una recopilación de recursos que facilitan el acceso libre a obras:

http://bibliotecnica.upc.es/sepi/obres_CC.asp

10. http://es.creativecommons.org/licencia/

11. http://listserv.rediris.es/cgi-bin/wa?AO=iwetel

12. Téngase aen cuenta que una infracción tipificada como grave puede ser sancionada con hasta $600.000 €$.

http://www.icemd.com/area-entrada/noticias/consulta-not. asp? $I d=180 \& T E M A=8$

13. http://www.madrid.org/comun/datospersonales/0,3126,457237_458340_ 127535941_12415800_12411900,00.html

14. https://www.agpd.es/index.php

15. Agència Catalana de Protecció de Dades: http://www.apdcat.net

Agencia de Protección de Datos de la Comunidad de Madrid:

http://www.madrid.org/apdcm

Agencia Vasca de Protección de Datos:

http://www.avpd.euskadi.net/s04-4319/es/

\section{Bibliografía}

Agencia de Protección de datos de la Comunidad de Madrid (Apdcm). "Extracto de la Resolución relativa a si la lectura pública de las calificaciones de los alumnos de una Universidad pública de la Comunidad de Madrid realizada en el Campus de la Universidad constituye una vulneración del deber de secreto establecido en la normativa de protección de datos de carácter personal". En: Datospersonales.org, 2005, mayo, n. 15. Consultado en: 10-08-06

http://www.madrid.org/comun/datospersonales/0,3126,457237_458334_ 127535941_12365691_12360000,00.html

Agencia de Protección de datos de la Comunidad de Madrid (Apdcm). "Consulta relativa a la posibilidad de publicar en la web de una Universidad datos de sus trabajadores". En: Datospersonales.org, 2005, mayo, n. 15. Consultado en: 10-08-05.

http://www.madrid.org/comun/datospersonales/0,3126,457237_458334_ 127535941_12365319_12360000,00.html

Agencia de Protección de datos de la Comunidad de Madrid (Apdcm). Cua- 
derno de protección de datos personales para empleados públicos. Madrid: Apdcm, [200?]. Consultado en: 04-08-06.

http://www.madrid.org/staticFiles/site_97778857/cit_13710/cuaderno.pdf

Agencia Española de Protección de Datos (AEPD). Informe: dirección de correo electrónico. 1999. Consultado en: 05-08-06.

https://www.agpd.es/upload/Canal_Documentacion/Informes $\% 20$ Juridicos/Otras\%20cuestiones\%20de\%20interes/OC\%20(1999-0000)\%20 (Direcci\%F3n\%20de\%20correo\%20 lectr\%F3nico).pdf\#search $=\% 22$ dire ccion\%20de\%20correo\%20lectronico\%20a\%C3\%B1o\%201999\%22

Altarriba, Núria. "Els drets d'autor". En: Item: revista de biblioteconomia i documentació, 1997, n. 21. Consultado en: 14-08-06.

http://www.raco.cat/index.php/Item/article/view/22512/22346

Asís Roig, Agustín E. de. "Protección de datos y derecho de las telecomunicaciones". En: Régimen jurídico de internet. Las Rozas (Madrid): La Ley, 2002. ISBN 84-9725-147-4.

Battaner, Santiago. "Origen y consecuencias jurídicas del tratamiento de datos especialmente protegidos". En: Datospersonales.org, 2005, n. 18 Consultado en 07-08-06.

http://www.madrid.org/comun/datospersonales/0,3126,457237_458340_ 127535941_12415800_12411900,00.html

Bercovitz Rodríguez-Cano, Rodrigo (coord.). Comentarios a la ley de propiedad intelectual: real decreto legislativo 1/1996. de 12 de abril, por el que se aprueba el Texto Refundido de la Ley de Propiedad Intelectual, regularizando, aclarando y armonizando las disposiciones legales vigentes sobre la materia. $2^{a}$ ed. Madrid: Tecnos, 1997. ISBN 84-309-2998-3.

Bowers, Stacey L. "Privacy and library records". En: The journal of Academia Librarianship, 2006, v. 32 n. 4

Clavell Vergés, Gaspar. "La propiedad intelectual e internet: su subordinación a la cultura y a la información". En: Cuadernos de documentación multimedia, 1999, n. 8. Consultado en: 15-08-06.

http://www.ucm.es/info/multidoc/multidoc/revista/num8/gaspar.html

Conde Ortiz, Concepción. La protección de datos personales. Dykinson, 2006. ISBN: 84-9772-597-2.

Fernández-Galiano, Blanca. "Los límites al acceso a las historias clínicas”. En: Datospersonales.org, 2006, n. 21. Consultado en: 07-08-06. http://www.madrid.org/comun/datospersonales/0,3126,457237_458340_ 460419_12454930_12453811_1,00.html

Herrán Ortíz, Ana Isabel. El derecho a la intimidad en la nueva Ley or- gánica de protección de datos personales. Madrid: Dykinson, 2002. ISBN 84-8155-869-9.

López-Vidriero Tejedor, Iciar; Santos Pascual, Efrén. Protección de datos personales: manual práctico para empresas. Madrid: Fundación Confemetal, 2005. ISBN 84-96169-63-4.

Quinto, Francisco de. “Cuándo puedo o debo destruir los datos personales?". En: Revista documentación digital, 2006, n. 7. Consultado en: 0508-06.

http://www.lodging.es/archivos/RDD_7\%20PDF\%20bo2.pdf\#search=\%22 revista\%20documentacion\%20digital\%20quinto\%22

Riera Barsallo, Patricia. "La reforma de la llei de propietat intel-lectual: canvis produits per la transposició de la directiva sobre drets d'autor". En: Bibliodoc, anuari de biblioteconomia, documentació i informació, 2005.

Rodríguez Tapia, J. Miguel; Bondia Román, Fernando. Comentarios a la ley de propiedad intelectual: texto refundido R. D. Leg. 1/1996, de 12 de abril. Madrid: Civitas, 1997. ISBN 84-470-0896-7.

Rogel Vide, Carlos. La duración de la propiedad intelectual y las obras en dominio público. Madrid: Reus, 2005. ISBN 84-290-1417-9.

Toniatti, Roberto. "Libertad informática y derecho a la protección de los datos personales: principios de legislación comparada". En: Revista vasca de administración pública, 1991, enero-abril, n. 29

Vives-Gràcia, Josep. "Aspectos de propiedad intelectual en la creación y gestión de repositorios institucionales". En: El profesional de la información, 2005, v. 14, n. 4, pp. 267-278. Consultado en: 20-08-06.

http://www.elprofesionaldelainformacion.com/contenidos/2005/julio/267. $p d f$

Vives-Gràcia, Josep. "Guia bàsica de propietat intel-lectual per a biblioteques”. En: Item: revista de biblioteconomia i documentació, 2005, n. 38, pp. 103-152. Consultado en: 20-08-06.

http://eprints.rclis.org/archive/00003669/01/Guia_b\%C3\%A0sica_de_propietat_intel\%C2\%B7lectual_per_a_biblioteques.pdf

Josep Vives-Gràcia, Biblioteca de l'Epsevg, Universitat Politècnica de Catalunya, Barcelona.

josep.ferran.vives@upc.edu http:/bibliotecnica.upc.es/bib340/

\section{Próximos temas centrales} Julio 2007 Bibliotecas universitarias Septiembre 2007 Documentación multimedia Noviembre 2007 Ontologías Enero 2008 Software libre para bibliotecas Marzo 2008 Innovación en bibliotecas públicas

Los interesados pueden remitir notas, artículos, propuestas, publicidad, comentarios, etc., sobre estos temas a: epi@elprofesionaldelainformacion.com 